\title{
Growth pattern change of a benign clear cell 'sugar' tumor of the lung: Serial imaging surveillance over seven years
}

\author{
EUNG KOO YEON $^{1}$, JUNG IM KIM ${ }^{2}$, KYU YEOUN WON $^{3}$ and HAN NA LEE ${ }^{2}$ \\ ${ }^{1}$ Department of Radiology, Kyung Hee University Medical Center, Seoul 02447; \\ Departments of ${ }^{2}$ Radiology and ${ }^{3}$ Pathology, Kyung Hee University Hospital at Gangdong, \\ College of Medicine, Kyung Hee University, Seoul 05278, Republic of Korea
}

Received November 9, 2017; Accepted March 16, 2018

DOI: $10.3892 / \mathrm{ol} .2018 .8391$

\begin{abstract}
Clear cell tumor of the lung is a rare benign mesenchymal tumor and only sporadic cases have been previously reported. The present study reports the case of a 58 -year-old man who presented with an incidentally detected solitary pulmonary nodule. Based on comparisons with serial previous chest and spine radiographs, a growth pattern change in the nodule (initial gradual growth over 4.5 years, then recent no growth over 2.5 years) was identified. The nodule was diagnosed as a benign clear cell tumor of the lung (CCTL) following surgical resection. Few studies have previously reported interval growth of CCTLs and the growth pattern of CCTL is not yet well known. To the best of our knowledge, this is the first reported case in which the growth pattern change of CCTL was identified via serial imaging over 7 years of follow-up.
\end{abstract}

\section{Introduction}

Clear cell tumor, also known as 'sugar' tumor, belongs to the family of perivascular epithelial cell tumors (PEComas) and can originate from various organs in the body, such as the rectum, pancreas, heart, salivary gland, trachea and lung $(1,2)$. Clear cell tumor of the lung (CCTL) was first described by Liebow and Castleman (3) in 1963 and is generally regarded as an extremely rare benign mesenchymal lung tumor. It is usually incidentally detected on routine check-up chest radiograph as a solitary pulmonary nodule. There are no significant findings in physical examinations and laboratory studies although only a few patients displayed symptoms (headaches, weakness, cough, bloody sputum, hemoptysis, chest pain, essential thrombocytosis and unexplained high fever) (4). Only a few sporadic cases have been reported and study of the interval growth of

Correspondence to: Dr Jung Im Kim, Department of Radiology, Kyung Hee University Hospital at Gangdong, College of Medicine, Kyung Hee University, 892 Dongnam-Ro, Gangdong-Gu, Seoul 05278, Republic of Korea

E-mail: mine147@gmail.com

Key words: clear cell tumor, sugar tumor, growth pattern this tumor is extremely limited. The present study reports a CCTL that exhibited growth pattern change on follow-up imaging studies over 7 years along with a review of the literature. The present case study was approved by the Kyung Hee University Hospital at Gangdong Institutional Review Board (Seoul, Korea) and the patient provided informed written consent for the publication of the present study.

\section{Case report}

A 58-year-old man was admitted to our hospital for further evaluation of an incidentally detected nodular opacity on routine check-up chest radiograph. Physical and laboratory examinations did not exhibit any abnormalities. He was a 35-pack-year current smoker and had a history of diabetes mellitus. On chest radiograph, a round and well-defined nodular opacity was identified in the left lower lung field (Fig. 1A). Contrast-enhanced chest computed tomography (CT) demonstrated a $2.7 \mathrm{~cm}$ nodule in the left lower lobe, and the nodule showed strong homogeneous contrast enhancement (Fig. 1B). There was no definite cavitation or necrosis. The nodule was retrospectively traced on whole spine radiography that was performed to evaluate back pain 18 months ago (Fig. 1C). The maximal diameter of the nodule was $2.6 \mathrm{~cm}$, and there was no significant interval change in size over 18 months. Because the patient was unwilling to proceed with further evaluation of the nodule and the nodule was stable, the patient was decided to undergo serial observation.

One year later, the patient underwent follow-up evaluation. The nodule showed no significant interval change in size on chest radiographs (Fig. 1D). However, he brought his old chest radiographs from an outside hospital, in which the nodule had showed slow interval growth from 1.3 to $2.6 \mathrm{~cm}$ over 4.5 years (Fig. 2A-D).

Although there was no significant interval change in size over the most recent 2.5 years, the malignant potential of the nodule was unknown because of previous interval growth. Therefore, the nodule was resected by video-assisted thoracoscopic wedge resection.

The gross specimen reveals a well-defined nodule measuring $2.7 \mathrm{~cm}$ in diameter without evidence of cavitation, hemorrhage, or calcification. Microscopically, the tumor consisted of rounded cells with clear to pale eosinophilic cytoplasm rich in periodic acid-Schiff (PAS)-positive 

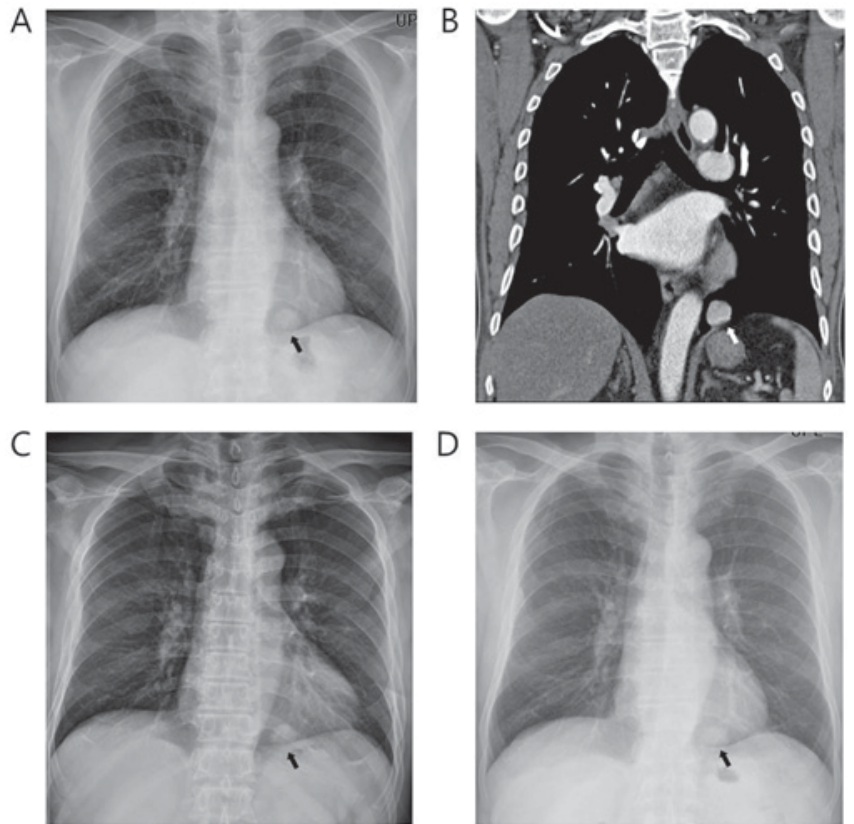

Figure 1. (A) Chest radiograph showing a solitary pulmonary nodule (black arrow) in the left lower lung field with a $2.7 \mathrm{~cm}$ diameter. (B) Contrast-enhanced CT scan exhibiting a round, well-defined, strongly homogenous enhanced nodule (white arrow) in left lower lobe. (C) Whole spine radiograph performed 18 months ago demonstrating no significant interval change in nodule size (black arrow). (D) Follow-up chest radiograph taken 1 year later showing no significant interval change in nodule size (black arrow). CT, computed tomography.

glycogen granules (Fig. 3A, B). Immunohistochemial staining showed human melanoma black (HMB)-45, vimentin, and CD34 expression, but failed to express cytokeratin AE1/AE3, and epithelial membrane antigen (Fig. 3C). The tumor cells showed mild variation in nuclear size, but mitosis was not identified (Fig. 3D). On the basis of morphology and immunohistochemistry results, a diagnosis of CCTL was established. After surgical resection, the patient remained well with no evidence of local recurrence.

\section{Discussion}

CCTL is a very rare benign mesenchymal tumor with less than 60 cases reported in the English literature (5).The tumor can occur in any age group, although it affects elderly patients more often, and it has equal sex predilection with slight female predominance (1). According to the 2004 World Health Organization classification of lung tumors, CCTL belongs to the family of PEComas (1). The tumor consists of clear cells with a large amount of cytoplasmic periodic acid-Schiff (PAS)-positive glycogen; this is why the CCTL is also called sugar tumor. CCTL has distinguishable immunohistochemical features that include positivity for S-100 protein and human melanoma black (HMB)-45 and no reactivity for cytokeratin, an epithelial marker (6).

Most CCTLs have no symptoms and are usually incidentally discovered on routine chest radiography or CT scan (4). On chest radiographs, CCTLs present as a coin lesion or peripheral solitary nodule with well-defined smooth margins $(5,7)$. Because of the rich vascular stroma, most CCTLs show homogenous intense enhancement on CT scans. Kim et al (8), reported an
A
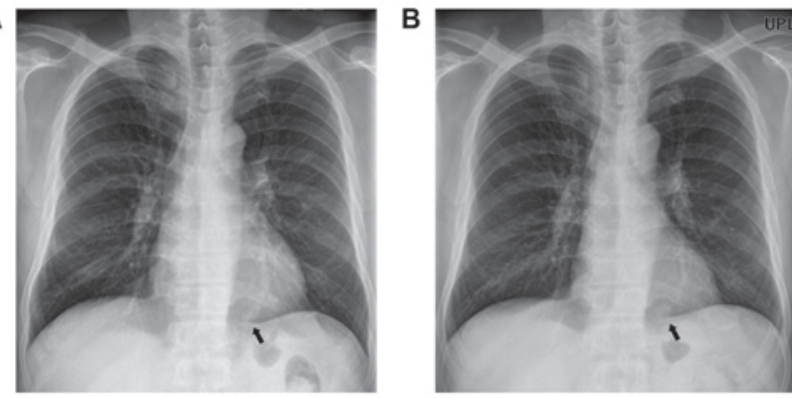

C
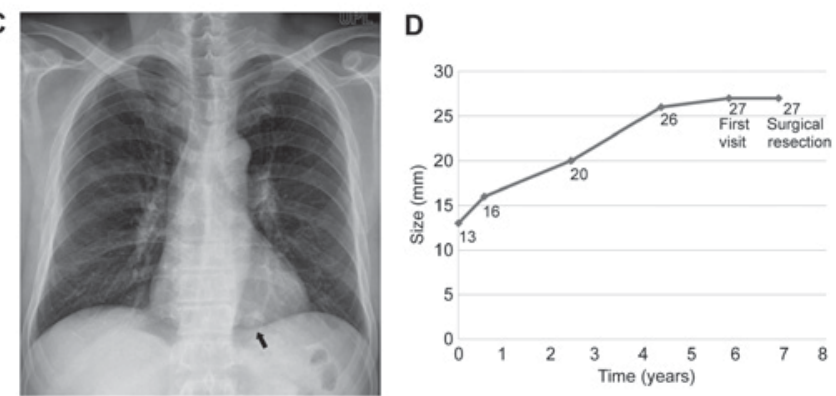

Figure 2. Previous chest radiograph performed (A) 7 years, (B) 6.5 years and (C) 4.5 years previously exhibiting gradual interval growth from 1.3 to $2.0 \mathrm{~cm}$ (black arrows). (D) Graph showing tumor size according to time over the course of 7 years.

A
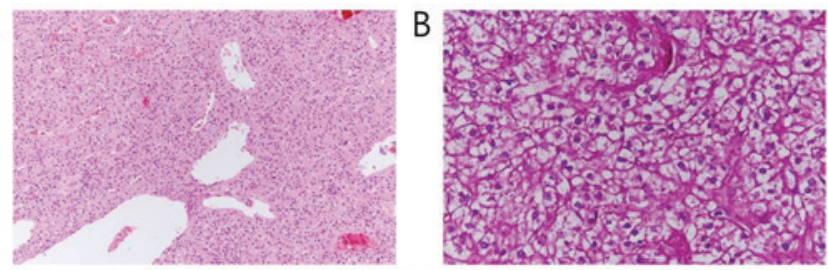

C
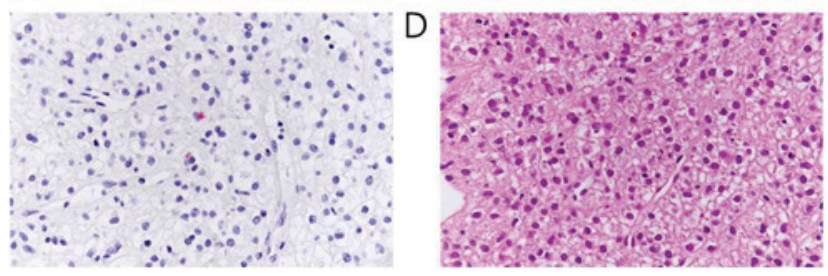

Figure 3. (A) Rounded cells with clear to pale eosinophilic cytoplasm formed solid sheets around sinusoidal blood vessels (magnification, $\mathrm{x} 40$ ). (B) Tumor cells had strong periodic acid-Schiff-positive cytoplasmic granules (magnification, x200). (C) Few melanosome (human melanoma black 45)-positive tumor cells were present (magnification, x200). (D) Tumor cells show mild variation in nuclear size, but mitosis was not identified (magnification, x200).

early wash-in and washout pattern of CCTL on dynamic CT. CCTLs usually show no ${ }^{18} \mathrm{~F}$-2-deoxy-D-glucose (FDG) uptake, but a $2.8-\mathrm{cm}$ benign CCTL that showed extensive FDG uptake has been reported (9).

Although CCTL is generally regarded as benign, there are some reports of CCTLs that exhibit malignant behavior in terms of local invasion or vascularity (10). Necrosis, mitotic index of 1 per 50 high-power fields, marked pleomorphism, and nuclear atypia also raise the possibility of malignant potential (11). It is difficult to definitively evaluate these pathological features by cytologic study such as fine needle aspiration or biopsy. Therefore, surgical resection is recommended for diagnosis and curative treatment (8). 
The rarity of CCTL and the paucity of published literature on CCTL makes it difficult to identify the interval growth pattern of CCTL. Only few cases have reported the interval growth of CCTLs. However, previous reports only stated an interval growth without mentioning the exact change in size $(9,12)$ or suggested a maximum volume doubling time estimated from initial normal chest radiograph (13). No previous reports remarked on serial imaging follow up of CCTL. Interestingly, CCTL showed a growth pattern change during 7 years of follow up in this case. On serial radiographs, the nodule initially showed linear gradual interval growth, but it remained $2.7 \mathrm{~cm}$ in diameter for the next 2.5 years. Although the limit of detectable changes in size on standard radiography has been estimated to be 3.0 to $5.0 \mathrm{~mm}$ (14), a reasonable assumption is that the nodule growth rate was extremely low during the past 2.5 years. We should keep in mind CCTL can show stable or aggressive behavior depending on the detection time and observation period. Growth pattern change and malignant potential of CCTL underlines the need of constant and close observation of these tumors.

\section{Acknowledgements}

Not applicable.

\section{Funding}

No funding was received.

\section{Availability of data and materials}

The datasets used and/or analyzed during the current study are available from the corresponding author on reasonable request.

\section{Authors' contributions}

JIK made substantial contributions to the conception and design of the study. EKY and HNL analyzed and interpreted the patient data regarding the follow up simple radiograph images and CT images and EKY was a major contributor in writing the manuscript. KYW performed the histological examination of the lung. All authors read and approved the final manuscript.

\section{Ethics approval and consent to participate}

The present case study was approved by the Kyung Hee University Hospital at Gangdong Institutional Review Board (Seoul, Korea).

\section{Consent for publication}

The patient provided written informed consent for the publication of their data.

\section{Competing interests}

The authors declare that they have no competing interests.

\section{References}

1. Travis WD, Brambilla E, Nicholson AG, Yatabe Y, Austin JHM, Beasley MB, Chirieac LR, Dacic S, Duhig E, Flieder DB, et al: The 2015 World Health Organization classification of lung tumors: Impact of genetic, clinical and radiologic advances since the 2004 classification. J Thorac Oncol 10: 1243-1260, 2015.

2. Tazelaar HD, Batts KP and Srigley JR: Primary extrapulmonary sugar tumor (PEST): A report of four cases. Mod Pathol 14: 615-622, 2001.

3. Liebow A and Castleman B: Benign clear cell ('sugar') tumors of the lung. Yale J Biol Med 43: 213-222, 1971.

4. Chen YB, Guo LC, Huang JA, Ji C and Ling CH: Clear cell tumor of the lung: A retrospective analysis. Am J Med Sci 347: 50-53, 2014.

5. Wang GX, Zhang D, Diao XW and Wen L: Clear cell tumor of the lung: A case report and literature review. World J Surg Oncol 11: 247, 2013.

6. Mizobuchi T, Masahiro N, Iwai N, Kohno H, Okada N and Nakada S: Clear cell tumor of the lung: Surgical and immunohistochemical findings. Gen Thorac Cardiovasc Surg 58: 243-247, 2010.

7. Das S, Cherian SV, Das N, Hamarneh WA, Singh Garcha A, Preet Singh P and Lenox R: A 52-Year-Old smoker with an incidental pulmonary nodule. Chest 141: 1346-1350, 2012.

8. Kim WJ, Kim SR, Choe YH, Lee KY, Park SJ, Lee HB, Chung MJ, Jin GY and Lee YC: Clear cell 'sugar' tumor of the lung: A well-enhanced mass with an early washout pattern on dynamic contrast-enhanced computed tomography. J Korean Med Sci 23: 1121-1124, 2008.

9. Zarbis N, Barth TF, Blumstein NM and Schelzig H: Pecoma of the lung: A benign tumor with extensive 18F-2-deoxy-D-glucose uptake. Interact Cardiovasc Thorac Surg 6: 676-678, 2007.

10. Kavunkal AM, Pandiyan MS, Philip MA, Parimelazhagan KN, Manipadam MT and Cherian VK: Large clear cell tumor of the lung mimicking malignant behavior. Ann Thorac Surg 83: 310-312, 2007.

11. Hornick JL and Fletcher CD: PEComa: What do we know so far? Histopathology 48: 75-82, 2006.

12. Mishina T, Suzuki I, Fujino M, Watanabe N, Akita H, Narita Y and Kawakami Y: A benign clear cell tumor of the lung that grew gradually over five years. Nihon Kyobu Shikkan Gakkai Zasshi 33: 765-770, 1995.

13. Kalkanis A, Trianti M, Psathakis K, Mermigkis C, Kalkanis D, Karagkiouzis G, Razou A and Tsintiris K: A clear cell tumor of the lung presenting as a rapidly growing coin lesion: Is it really a benign tumor? Ann Thorac Surg 91: 588-591, 2011.

14. Ost D, Fein AM and Feinsilver SH: Clinical practice. The solitary pulmonary nodule. N Engl J Med 348: 2535-2542, 2003. 